\title{
Breast fat and breast cancer
}

\author{
Andreas Pettersson ${ }^{1}$ and Rulla M Tamimi ${ }^{1,2}$ \\ ${ }^{1}$ Department of Epidemiology, Harvard School of Public Health, 677 Huntington Avenue, Boston, \\ MA 02115, USA \\ ${ }^{2}$ Channing Laboratory, Department of Medicine, Brigham and Women's Hospital and Harvard \\ Medical School, 181 Longwood Avenue, Boston, MA 02115, USA
}

\section{Keywords}

Breast Cancer; Mammography; Body Mass Index; Adipose Tissue; Risk

\section{Introduction}

There is a well-established association between high mammographic density and risk of breast cancer. We recently observed, somewhat to our surprise, a strong inverse association between the nondense area on a mammogram and risk of breast cancer [1]. In this paper, we briefly discuss this finding in the context of previous studies of mammographic density and breast cancer risk, as well as in context of prior findings of the association between excess body weight and breast cancer risk. We suggest that the notion that breast fat plays a protective role in breast carcinogenesis, at least during the premenopausal years, should be considered.

\section{Mammographic density and breast cancer risk}

Fibroglandular breast tissue is radiographically dense whereas adipose tissue is nondense. Mammographic density is commonly expressed as the percentage dense area. That is, the dense area divided by the total area on a mammogram (the dense area plus the nondense area). Compared to women with little or no dense area, women with $>75 \%$ dense area are at a $>4$-fold greater risk of breast cancer [2,3]. The biological mechanisms underlying this strong association are unknown, though it seems likely that the association can be explained at least partly by a positive correlation between percentage dense area and volume of fibroglandular tissue 'at risk' of developing breast cancer [4].

The absolute dense area on a mammogram is positively associated with breast cancer risk, in line with the notion that a greater volume of fibroglandular tissue is associated with a higher risk of breast cancer. Percentage dense area, however, appears to be an even stronger risk factor for breast cancer than absolute dense area in a number of studies [1]. At least two different, but not mutually exclusive, mechanisms can explain these observations. First, the percentage dense area is associated with breast cancer risk because it most accurately reflects the biological entity/mechanisms underlying the association between mammographic density and breast cancer risk. Second, the absolute dense area is associated with an increased risk of breast cancer, whereas the absolute nondense area is associated

Correspondence: Rulla M Tamimi, Phone: 617.525.0862, Fax: 617.525.2008, rulla.tamimi@ channing.harvard.edu.

None. 
with a decreased risk of breast cancer. In other words, percentage dense area is an as strong, or perhaps even stronger, risk factor for breast cancer than absolute dense area because it contains information on both the dense and the nondense area (i.e., the fibroglandular and fatty tissues).

Stuedal and colleagues observed that the positive association between absolute dense area and breast cancer risk diminishes with increasing total mammographic area, a proxy for breast size [5]. The authors proposed several explanations for their findings, including that breast fat have a direct beneficial effect on breast cancer risk. In a large case-control study, we observed that higher absolute dense area was associated with an increased risk of breast cancer independently of the absolute nondense area $\left(\mathrm{OR}_{\text {tertile }} 3\right.$ vs $1=2.01,95 \% \mathrm{CI}=1.45$ to 2.77 among premenopausal women; $\mathrm{OR}_{\text {quintile }} 5$ vs $1=2.19,95 \% \mathrm{CI}=1.65$ to 2.89 among postmenopausal women), whereas higher absolute nondense area was associated with a decreased risk of breast cancer independently of the absolute dense area $\left(\mathrm{OR}_{\text {tertile }} 3\right.$ vs $1=$ $0.51,95 \% \mathrm{CI}=0.36$ to 0.72 among premenopausal women; $\mathrm{OR}_{\text {quintile } 5 \text { vs } 1}=0.46,95 \% \mathrm{CI}$ $=0.34$ to 0.62 among postmenopausal women) [1]. Since adipose tissue is radiographically nondense, these results are in line with the hypothesis that breast fat protects against breast cancer. This association needs to be confirmed, however, as results from the few other studies that have assessed the association between absolute nondense area and breast cancer risk are mixed [6-8].

\section{Body mass index and breast cancer risk}

High body mass index (BMI; $\mathrm{kg} / \mathrm{m}^{2}$ ) is associated with an increased risk of postmenopausal breast cancer [9]. This association is largely explained by higher levels of estrogens in overweight or obese compared to normal weight postmenopausal women [10], because of aromatization of androgens to estrogens in peripheral adipose tissue. In premenopausal women, in contrast, high BMI is associated with a decreased risk of breast cancer [9]. This association is unexplained. In a review on the topic, Rose and Vona-Davis write: "In summary, there seems to be no doubt that obesity is associated with a reduction in premenopausal breast cancer risk, but the responsible mechanisms are unclear and the evidence from endocrine studies is inconsistent if not frankly contradictory" [11].

Higher BMI is associated with higher amounts of breast fat. A straightforward explanation to the decreased risk of breast cancer observed among premenopausal women with higher BMI is therefore that breast fat protects against breast cancer. If this hypothesis is correct, however, the question remains why higher BMI is associated with an increased risk of postmenopausal breast cancer? A possible explanation to this contradiction is that the adverse effect of higher BMI on breast cancer risk in postmenopausal women, mediated through higher levels of estrogens, outweighs the protective effect of increased amounts of breast fat.

\section{Mammographic density, body mass index, and breast cancer risk}

Higher BMI is associated with lower percentage dense area because the amount of breast fat/the nondense area increases with BMI. If higher amounts of breast fat protects against breast cancer, two findings are expected when the association between BMI and breast cancer risk is adjusted for the percentage dense area (Figure 1). The decreased risk of premenopausal breast cancer should disappear, or even turn into an increased risk, and the increased risk of postmenopausal breast cancer should get stronger. Two large case-control studies assessing the association between BMI and breast cancer risk adjusted for the percentage dense area have reported findings for premenopausal and/or postmenopausal breast cancer in line with these expectations $[12,13]$. 


\section{How can breast fat protect against breast cancer?}

In short, the breast microenvironment in fatty compared to dense breasts may promote normal mammary gland development and homeostasis, and hinder breast cancer development.

The adipose rich stromal environment in which the epithelial cells reside, the so called mammary fat pad, plays an important role in normal mammary gland development and function, and potentially in breast carcinogenesis [14]. For example, the mammary fat pad is a source of several proteins with cancer relevant properties, including insulin-like growth factor 1 (IGF-1), leptin and adiponectin. Breast adipose tissue may also store and bioactivate vitamin $\mathrm{D}$, which in its bioactive form has anti-carcinogenic effects [15]. It is also quite plausible that higher amounts of breast fat increase breast cancer risk [16], for example through high local estrogen production, but the role of breast fat in breast carcinogenesis has not been adequately investigated. There is thus insufficient data to draw firm conclusions of the net endocrine effect of high amounts of breast fat on breast carcinogenesis, and there is no strong evidence against the hypothesis that it is beneficial.

Increasing data suggests that extracellular matrix and tissue stiffness may initiate or promote breast cancer development [17-20]. For example, mammary epithelial cells cultured in stiff matrices show a phenotype and gene expression profile consistent with malignant transformation $[18,19]$. Indeed, several research groups have proposed that extracellular matrix and tissue stiffness, or quantitative or structural changes of the stromal collagen such as cross-linking, may partly explain the association between mammographic density and breast cancer risk $[19,21,22]$. If correct, increased amount of breast fat may directly or indirectly affect extracellular matrix and tissue stiffness, or the amount or structure of the stromal collagen, and thereby impact breast cancer risk. Lastly, breast tissue concentrations, or fluctuations in concentrations, of carcinogenic agents, including endogenous hormones and growth-factors, may be lower in fatty compared to dense breasts.

\section{Conclusion}

The percentage dense area on a mammogram, which is inversely related to BMI, is a strong risk factor for both premenopausal and postmenopausal breast cancer. High BMI is associated with an increased risk of postmenopausal breast cancer, but a decreased risk of premenopausal breast cancer. A possible explanation of these unexplained observations is that higher amounts of breast fat - via effects on normal mammary gland development, the breasts' endocrine milieu, stromal collagen and mechanical properties, or tissue concentrations of carcinogenic agents - have a protective role on breast carcinogenesis. We suggest that the notion that breast fat plays a protective role in breast carcinogenesis, at least during the premenopausal years, should be considered when investigating the etiology and carcinogenesis of breast cancer.

\section{Acknowledgments}

We thank Drs. Pagona Lagiou and Dimitrios Trichopoulos for valuable suggestions on the manuscript.

\section{References}

1. Pettersson A, Hankinson SE, Willett WC, Lagiou P, Trichopoulos D, Tamimi RM. Nondense mammographic area and risk of breast cancer. Breast Cancer Res. 2011; 13(5):R100. [PubMed: 22017857]

2. Byrne C, Schairer C, Wolfe J, et al. Mammographic features and breast cancer risk: effects with time, age, and menopause status. J Natl Cancer Inst. 1995; 87(21):1622-9. [PubMed: 7563205] 
3. McCormack VA, dos Santos Silva I. Breast density and parenchymal patterns as markers of breast cancer risk: a meta-analysis. Cancer Epidemiol Biomarkers Prev. 2006; 15(6):1159-69. [PubMed: 16775176]

4. Trichopoulos D, Lipman RD. Mammary gland mass and breast cancer risk. Epidemiology. 1992; 3(6):523-6. [PubMed: 1420519]

5. Stuedal A, Ma H, Bernstein L, Pike MC, Ursin G. Does breast size modify the association between mammographic density and breast cancer risk? Cancer Epidemiol Biomarkers Prev. 2008; 17(3): 621-7. [PubMed: 18349279]

6. Lokate M, Peeters PH, Peelen LM, Haars G, Veldhuis WB, van Gils CH. Mammographic density and breast cancer risk: the role of the fat surrounding the fibroglandular tissue. Breast Cancer Res. 2011; 13(5):R103. [PubMed: 22030015]

7. Stone J, Ding J, Warren RM, Duffy SW. Predicting breast cancer risk using mammographic density measurements from both mammogram sides and views. Breast Cancer Res Treat. 124(2):551-4. [PubMed: 20544272]

8. Torres-Mejia G, De Stavola B, Allen DS, et al. Mammographic features and subsequent risk of breast cancer: a comparison of qualitative and quantitative evaluations in the Guernsey prospective studies. Cancer Epidemiol Biomarkers Prev. 2005; 14(5):1052-9. [PubMed: 15894652]

9. Renehan AG, Tyson M, Egger M, Heller RF, Zwahlen M. Body-mass index and incidence of cancer: a systematic review and meta-analysis of prospective observational studies. Lancet. 2008; 371(9612):569-78. [PubMed: 18280327]

10. Key TJ, Appleby PN, Reeves GK, et al. Body mass index, serum sex hormones, and breast cancer risk in postmenopausal women. J Natl Cancer Inst. 2003; 95(16):1218-26. [PubMed: 12928347]

11. Rose DP, Vona-Davis L. Interaction between menopausal status and obesity in affecting breast cancer risk. Maturitas. 2010; 66(1):33-8. [PubMed: 20181446]

12. Boyd NF, Martin LJ, Sun L, et al. Body size, mammographic density, and breast cancer risk. Cancer Epidemiol Biomarkers Prev. 2006; 15(11):2086-92. [PubMed: 17119032]

13. Harris HR, Tamimi RM, Willett WC, Hankinson SE, Michels KB. Body size across the life course, mammographic density, and risk of breast cancer. Am J Epidemiol. 2011; 174(8):909-18. [PubMed: 21911827]

14. Hovey RC, Aimo L. Diverse and active roles for adipocytes during mammary gland growth and function. J Mammary Gland Biol Neoplasia. 2010; 15(3):279-90. [PubMed: 20717712]

15. Ching S, Kashinkunti S, Niehaus MD, Zinser GM. Mammary adipocytes bioactivate 25hydroxyvitamin D and signal via vitamin D receptor, modulating mammary epithelial cell growth. J Cell Biochem. 2011; 112(11):3393-405. [PubMed: 21769914]

16. Beer AE, Billingham RE. Adipose tissue, a neglected factor in aetiology of breast cancer? Lancet. 1978; 2(8084):296. [PubMed: 79087]

17. Levental KR, Yu H, Kass L, et al. Matrix crosslinking forces tumor progression by enhancing integrin signaling. Cell. 2009; 139(5):891-906. [PubMed: 19931152]

18. Paszek MJ, Zahir N, Johnson KR, et al. Tensional homeostasis and the malignant phenotype. Cancer Cell. 2005; 8(3):241-54. [PubMed: 16169468]

19. Provenzano PP, Inman DR, Eliceiri KW, Keely PJ. Matrix density-induced mechanoregulation of breast cell phenotype, signaling and gene expression through a FAK-ERK linkage. Oncogene. 2009; 28(49):4326-43. [PubMed: 19826415]

20. Ronnov-Jessen L, Bissell MJ. Breast cancer by proxy: can the microenvironment be both the cause and consequence? Trends Mol Med. 2009; 15(1):5-13. [PubMed: 19091631]

21. Brower V. Homing in on mechanisms linking breast density to breast cancer risk. J Natl Cancer Inst. 2010; 102(12):843-5. [PubMed: 20530764]

22. Butcher DT, Alliston T, Weaver VM. A tense situation: forcing tumour progression. Nat Rev Cancer. 2009; 9(2):108-22. [PubMed: 19165226] 


\section{a) Postmenopausal women}

\section{Circulating and local estrogens}

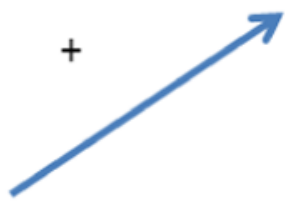

BMI

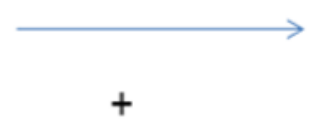

Breast adipose tissue

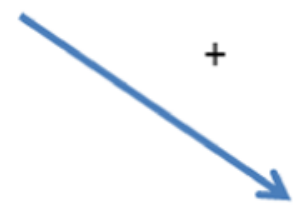

\section{b) Premenopausal women}

BMI

Breast adipose tissue

Breast cancer

$+$

Figure 1.

A hypothesized directed acyclic graph (DAG) of the association between BMI and breast cancer. (a) In postmenopausal women, the positive association between BMI and breast cancer risk is mediated primarily through increased amounts of estrogens. (b) In premenopausal women, the inverse association between BMI and breast cancer risk is mediated primarily through protective effects of higher amounts of breast adipose tissue. 